\title{
APLIKASI SMS GATEWAY SEBAGAI PENDUKUNG SISTEM INFORMASI PEMESANAN PAKET WISATA BERBASIS E-TOURISM
}

\author{
Sardiarinto \\ Teknologi Komputer, Fakultas Teknologi Informasi \\ Universitas Bina Sarana Informatika Kampus Banyumas \\ sardiarinto.sdo@bsi.ac.id
}

\begin{abstract}
At present Indonesia is ranked as the 5th most internet user in the world. The internet has become a major requirement. The tourism sector is a very potential sector to be developed as a source of regional income. Factors supporting the tourism sector that are not less important are tour package providers. This sector has a very important role in a tourist destination. One of the supporting facilities that must be provided for the tourism sector is the information needs of tourist destinations and supporting facilities. Information to be provided must be supported by technology that can be given various requests from users. SMS Gateway can be interpreted as an additional device used to send and receive messages or messages sent by telephone to a computer or network provider. With the advancement of SMS Gateway technology at this time, making the long-distance as an obstacle in communication. The use of this technology has been widely used in business circles in Indonesia. With the speed of this information etourism-based, Tourism Information System was developed with the support of SMS Gateway using the $R A D$ (Rapid Application Development) model. Applications that can be used to serve various requests from users and can facilitate various communities and can be used to obtain more valid, accurate and fast information.
\end{abstract}

Keywords: E-Tourism, Booking Tour Packages, SMS Gateway

\section{ABSTRAK}

Saat ini Indonesia menduduki peringkat 5 pengguna internet terbanyak di seluruh dunia. Internet telah menjadi sebuah kebutuhan yang pokok. Sektor pariwisata merupakan sektor yang sangat potensial untuk dikembangkan sebagai salah satu sumber pendapatan daerah. Faktor pendukung sektor pariwisata yang tak kalah penting adalah penyedia paket wisata. Sektor ini memiliki peranan yang sangat penting dalam mempromosikan suatu destinasi wisata. Salah satu fasilitas pendukung terpenting yang harus disediakan untuk sektor pariwisata adalah kebutuhan informasi terhadap tujuan wisata dan fasilitas-fasilitas pendukungnya. Informasi yang akan diberikan harus didukung dengan teknologi yang dapat melayani berbagai permintaan dari para pengguna. SMS Gateway dapat diartikan sebagai sebuah perangkat lunak tambahan yang digunakan untuk memudahkan pengiriman dan penerimaan teks atau pesan melalui jaringan telepon selular dari sebuah komputer atau jaringan. Dengan kemajuan teknologi SMS Gateway saat ini, menjadikan jarak bukanlah sebagai penghambat dalam melakukan komunikasi. Pemanfaatan teknologi ini sudah banyak digunakan dalam kalangan bisnis di Indonesia. Dengan kecepatan informasi tersebut maka dikembangkanlah sebuah Sistem Informasi Pariwisata Berbasis e-tourism dengan dukungan SMS Gateway menggunakan model RAD(Rapid Application Development). Sehingga aplikasi dapat digunakan untuk melayani berbagai akses permintaan dari para pengguna serta dapat menjangkau berbagai lapisan masyarakat dan dapat dimanfaatkan untuk mendapatkan informasi yang lebih valid, akurat dan cepat.

\section{Kata Kunci : E-Tourism, Pemesanan Paket Wisata, SMS Gateway}

\section{PENDAHULUAN}

Saat ini internet telah menjadi kebutuhan yang pokok yang tidak dapat dipungkiri. Terbukti setiap tahunnya semakin banyak jumlah individu yang mengakses internet dari berbagai macam media mulai dari smart phone, tablet, laptop dan juga komputer PC. Merujuk hasil dari survei APJII, untuk pengguna internet di Indonesia pada tahun 2018 telah mencapai $64,8 \%$ dari total populasi keseluruhan indonesia (APJII, 2019).

Indonesia merupakan negara yang memiliki populasi cukup tinggi diikuti dengan tingkat penggunaan internet. Berdasarkan data dari Internet World Stats, saat ini Indonesia menduduki peringkat ke-5 sebagai pengguna internet terbanyak di seluruh dunia. 
Tabel 1. Top 20 Countries With The Highest Number of Internet Users

\begin{tabular}{|c|c|c|c|c|c|c|}
\hline \multicolumn{7}{|c|}{$\begin{array}{c}\text { TOP } 20 \text { COUNTRIES WITH HIGHEST NUMBER OF } \\
\text { INTERNET USERS - MAY } 31,2019\end{array}$} \\
\hline$\#$ & Country or Region & $\begin{array}{l}\text { Population, } \\
2019 \text { Est. }\end{array}$ & $\begin{array}{l}\text { Population } \\
2000 \text { Est. }\end{array}$ & $\begin{array}{c}\text { Internet Users } \\
31 \text { Mar } 2019\end{array}$ & $\begin{array}{l}\text { Internet Users } \\
31 \text { Dec } 2000\end{array}$ & $\begin{array}{c}\text { Internet Growth } \\
2000-2019\end{array}$ \\
\hline 1 & China & $1,420,062,022$ & $1,283,198,970$ & $829,000,000$ & $22,500,000$ & $3,584 \%$ \\
\hline 2 & India & $1,368,737,513$ & $1,053,050,912$ & $560,000,000$ & $5,000,000$ & $11,100 \%$ \\
\hline 3 & United States & $329,093,110$ & $281,982,778$ & $292,892,868$ & $95,354,000$ & $207 \%$ \\
\hline 4 & Brazil & $212,392,717$ & $175,287,587$ & $149,057,635$ & $5,000,000$ & $2,881 \%$ \\
\hline 5 & Indonesia & $269,536,482$ & $211,540,429$ & $143,260,000$ & $2,000,000$ & $7,063 \%$ \\
\hline 6 & Japan & $126,854,745$ & $127,533,934$ & $118,626,672$ & $47,080,000$ & $152 \%$ \\
\hline 7 & Nigeria & $200,962,417$ & $122,352,009$ & $111,632,516$ & 200,000 & $55,716 \%$ \\
\hline 8 & Russia & $143,964,709$ & $146,396,514$ & $109,552,842$ & $3,100,000$ & $3,434 \%$ \\
\hline 9 & Bangladesh & $168,065,920$ & $131,581,243$ & $92,061,000$ & 100,000 & $91,961 \%$ \\
\hline 10 & Mexico & $132,328,035$ & $101,719,673$ & $85,000,000$ & $2,712,400$ & $3,033 \%$ \\
\hline 11 & Germany. & $82,438,639$ & $81,487,757$ & $79,127,551$ & $24,000,000$ & $229 \%$ \\
\hline 12 & Turkey. & $82,961,805$ & $63,240,121$ & $69,107,183$ & $2,000,000$ & $3,355 \%$ \\
\hline 13 & Philippines & $108,106,310$ & $77,991,569$ & $67,000,000$ & $2,000,000$ & $3,250 \%$ \\
\hline 14 & Vietnam & $97,429,061$ & $80,285,562$ & $64,000,000$ & 200,000 & $31,900 \%$ \\
\hline 15 & United Kingdom & $66,959,016$ & $58,950,848$ & $63,061,419$ & $15,400,000$ & $309 \%$ \\
\hline 16 & Iran & $82,503,583$ & $66,131,854$ & $62,702,731$ & 250,000 & $24,981 \%$ \\
\hline 17 & France & $65,480,710$ & $59,608,201$ & $60,421,689$ & $8,500,000$ & $610 \%$ \\
\hline 18 & Thailand & $69,306,160$ & $62,958,021$ & $57,000,000$ & $2,300,000$ & $2,378 \%$ \\
\hline 19 & Italy. & $59,216,525$ & $57,293,721$ & $54,798,299$ & $13,200,000$ & $315 \%$ \\
\hline 20 & Egypt & $101,168,745$ & $69,905,988$ & $49,231,493$ & 450,000 & $10,613 \%$ \\
\hline \multicolumn{2}{|c|}{ TOP 20 Countries } & $5,187,499,066$ & $4,312,497,691$ & $3,117,533,898$ & $251,346,400$ & $1,140 \%$ \\
\hline \multicolumn{2}{|c|}{ Rest of the World } & $2,565,984,143$ & $1,832,509,298$ & $1,229,027,955$ & $109,639,092$ & $1,021 \%$ \\
\hline \multicolumn{2}{|c|}{ Total World } & $7,716,223,209$ & $6,145,006,989$ & $4,383,810,342$ & $360,985,492$ & $1,104 \%$ \\
\hline
\end{tabular}

Sumber: Internet World Stats(2019)

Sektor pariwisata di Indonesia memberikan sumbangan yang besar bagi peningkatan devisa negara dan lapangan kerja. Kegiatan di sektor pariwisata juga berperan besar dalam memberikan sumbangan untuk pendapatan suatu daerah. Sektor ini juga memberikan dampak sosial, ekonomi, budaya dan sumber daya alam. Pariwisata sangat berperan dalam proses pembangunan dan pengembangan wilayah yang memiliki potensi wisata (Arsul, Lumenta, \& Sugiarso, 2015). Sektor pariwisata merupakan sektor yang sangat potensial untuk dikembangkan sebagai salah satu sumber untuk meningkatkan pendapatan daerah. Untuk itu program pengembangan dan pendayagunaan sumber daya dan potensi pariwisata daerah diharapkan dapat memberikan sumbangan bagi pembangunan ekonomi.

Faktor pendukung sektor pariwisata yang tak kalah penting adalah penyedia paket wisata. Sektor ini memiliki peranan yang sangat penting dalam mempromosikan suatu destinasi wisata. Ketika wisatawan menggunakan jasa pelayanan penyedia paket wisata, maka secara otomatis mereka akan ditawarkan banyak macam pilihan paket wisata. Saat ini para wisatawan mulai berfikir untuk membuat agenda perjalanan mereka secara rapi dengan cara memilih beberapa destinasi wisata yang mungkin dapat dikunjungi dalam satu hari penuh. Hal ini bertujuan agar kegiatan liburan mereka dapat berjalan efektif, efisien dengan mengeluarkan biaya yang tidak terlalu banyak. (Machdalena, Dewi, \& Soemantri, 2018).

Berwisata bagi sebagian besar orang sudah menjadi kebutuhan yang tidak dapat di hindari. Mulai dari kebutuhan akan jalan-jalan ke berbagai tempat hingga menikmati kuliner menjadi tujuan utama berwisata. Salah satu fasilitas pendukung terpenting yang harus disediakan untuk sektor pariwisata adalah kebutuhan informasi terhadap tujuan wisata dan fasilitas-fasilitas pendukung lainnya. Informasi yang akan diberikan harus didukung dengan teknologi yang dapat melayani berbagai permintaan dari para pengguna. Penggunaan teknologi ini harus dapat menjangkau berbagai lapisan masyarakat dan daerah. Salah satunya dapat dilakukan dengan pemesanan secara online dengan pilihan-pilihan yang sesuai dengan keinginan pengguna. Dengan kata lain seorang konsumen akan mendapatkan informasi yang lebih cepat, akurat dan valid pastinya sehingga mereka secara langsung dapat memutuskan mana yang akan menjadi tujuannya.

SMS Gateway dapat diartikan sebagai sebuah perangkat lunak tambahan yang 
digunakan untuk memudahkan pengiriman dan penerimaan teks atau pesan melalui jaringan telepon selular dari sebuah komputer atau jaringan (Sriyanto \& Sriyusielani, 2014). Dengan kemajuan teknologi SMS Gateway saat ini, menjadikan jarak bukanlah sebagai penghambat dalam melakukan komunikasi. Pemanfaatan teknologi ini sudah banyak digunakan dalam kalangan bisnis salah satu contohnya adalah Bank. Saat ini semua Bank sudah menggunakan SMS Gateway untuk memberikan infomasi kepada nasabah dalam transaksi banking. Sehingga nasabah mendapat informasi detail tentang jumlah saldo dan juga penarikan uang (Afrina \& lbrahim, 2015).

Dengan kecepatan informasi tersebut maka perlu dikembangkan sebuah Sistem Informasi Pariwisata Berbasis e-tourism dengan dukungan SMS Gateway dapat digunakan melayani berbagai akses permintaan dari para pengguna serta dapat menjangkau berbagai lapisan masyarakat dan dapat dimanfaatkan oleh berbagai pengguna untuk mendapatkan informasi yang lebih valid, akurat dan cepat.

\section{METODOLOGI PENELITIAN}

Dalam pembangunan sistem ini menggunakan metode RAD(Rapid Application Development). Model RAD merupakan proses pengembangan perangkat lunak yang menekannkan pengembangan siklus yang sangat pendek. Model ini merupakan pengembangan atau adaptasi dari model sequentisl linear/waterfall (Utami \& Asnawati, 2015).

Adapun langkah-langkah atau tahapan dalam membangun aplikasi dengan model RAD adalah sebagai berikut (Utami \& Asnawati, 2015):

1. Pemodelan Bisnis

Pada tahap ini berisi tentang apa

informasinya, siapa yang menghasilkan, siapa yang memproses dan dari mana informasinya.

2. Pemodelan data

Merupakan tahap identifikasi karakteristik serta hubungan antar objek.

3. Pemodelan Proses

Objek data yang sudah di identifikasi dihubungkan untuk melaksanakan fungsi tersebut.

4. Generalisasi Aplikasi

Merupakan Proses penggunaan Bahasa pemrograman untuk mnghasilkan aplikasi yang diinginkan.

5. Pengujian
Program yang sudah di bentuk dilakukan pengujian untuk menguji komponen dan interfacenya.

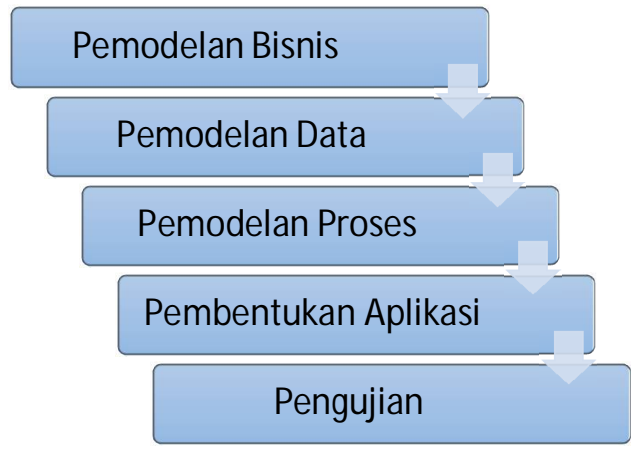

\section{Pembahasan}

Gambar 2. Metode RAD(Rapid Application Development )

\subsection{Pemodelan Bisnis}

Program aplikasi yang diusulkan yakni sebuah aplikasi berbasis web dengan dukungan SMS Gateway. Aplikasi SMS Gateway berperan sebagai pengolah informasi, dimana informasi tersebut dikemas dalam bentuk SMS. Aplikasi SMS Gateway ini dijalankan pada sebuah komputer yang terhubung dengan database dan menggunakan sebuah handphone/modem yang dihubungkan melalui USB port sebagai penerima SMS. Aplikasi ini akan menerima semua SMS yang masuk dan meresponnya secara otomatis. Bentuk pemodelan bisnis digambarkan dalam Use Case berikut:

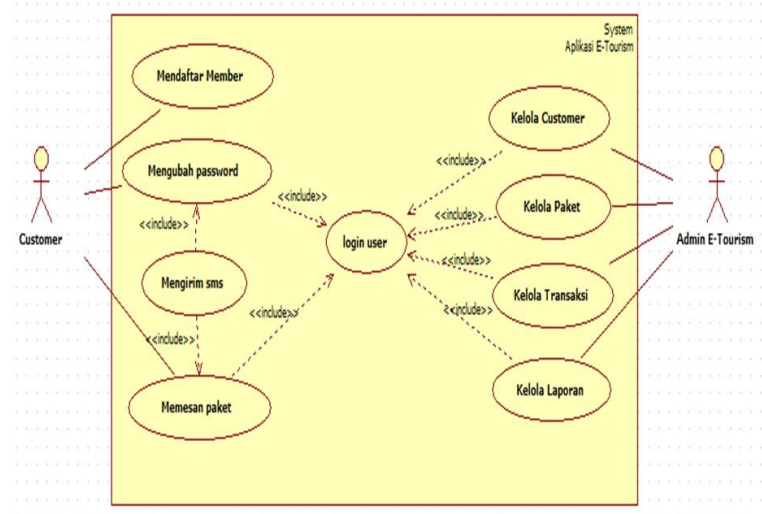

Gambar 3. Pemodelan Bisnis

Beberapa tahapan-tahapan yang dilakukan dalam proses bisnis pada aplikasi ini adalah:

1. Analisa Kebutuhan Pengguna Customer

a. Customer dapat menjadi member seteleh melakukan pendaftaran.

b. Customer dapat mengubah password dengan cara login terlebih dahulu dan 
memasukkan kode verifikasi dari sms yang diterima ke aplikasi.

c. Customer dapat memesan paket wisata yang disediakan di aplikasi

d. Customer dapat menerima informasi pemesanan melalui sms

2. Analisa Kebutuhan Pengguna Admin

a. Admin dapat mengelola Customer dengan cara login terlebih dahulu

b. Admin dapat mengelola Daftar Paket Wisata dengan cara login terlebih dahulu

c. Admin dapat mengelola Transaksi Pemesanan dengan cara login terlebih dahulu

d. Admin dapat mengelola Laporan dengan cara login terlebih dahulu

3. Analisa Kebutuhan Sistem

Setelah Customer mengedit password atau memesan paket tour, aplikasi membuat kode acak untuk verifikasi dengan menyimpan kode tersebut kedalam database. Kemudian aplikasi SMS Gateway akan mengambil kode tersebut untuk dikirimkan melalui sms ke customer.

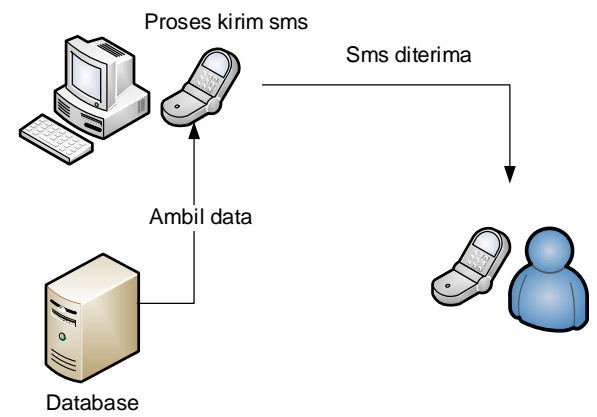

Gambar 4. Proses Mengirim sms

\subsection{Pemodelan Data}

Gammu dapat menggunakan database MySQL, PostgreSQL, bahkan gammu juga menyertakan library untuk mengakses database seperti SQLite, Ms.SQL Server, Sybase, Firebird, dan lain-lain. Dalam penulisan ini menggunakan database mysql dengan tabel sebagai berikut:

\section{Tabel Utama}

Merupakan tabel yang di rancang untuk melakukan transaksi yang terdiri dari tabel Customer, TourPackage, dan Transaction.

Tabel 2. Tabel Customer

\begin{tabular}{|l|l|l|}
\hline Field Name & Datatype & Len \\
\hline CUSTOMERID & varchar & -6 \\
\hline NAME & varchar & -40 \\
\hline A.DDRESS & varchar & -200 \\
\hline HP & varchar & -15 \\
\hline REKENING & varchar & -30 \\
\hline BANK & varchar & -50 \\
\hline PASS & varchar & -20 \\
\hline
\end{tabular}

ISSN: 2338-8145 (Print), 2338-9761 (Online)
Tabel Customer digunakan untuk menampung data customer yang menjadi anggota.

Tabel 3. Tabel TourPackage

\begin{tabular}{|c|c|c|c|}
\hline Field Name & Datatype & & Len \\
\hline TOURCODE & varchar & 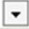 & 6 \\
\hline DESTINATION & varchar & 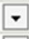 & 50 \\
\hline DURATION & varchar & 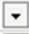 & 20 \\
\hline CATEGORY & varchar & $\nabla$ & 50 \\
\hline PRICE & float & 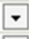 & \\
\hline DESCRIPIION & varchar & $\checkmark$ & 200 \\
\hline
\end{tabular}

Tabel TourPackage digunakan untuk menampung data daftar paket wisata yang ditawarkan pada aplikasi e-tourism.

Tabel 4. Tabel Transaction

\begin{tabular}{|c|c|c|c|}
\hline Field Name & Datatype & & Ien \\
\hline TRANSCID & int & 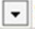 & 11 \\
\hline DATE & date & - & \\
\hline CUSTOMERID & varchar & + & 6 \\
\hline TOURCODE & varchar & - & 6 \\
\hline PRICE & float & - & \\
\hline STATUS & varchar & - & 10 \\
\hline REK & varchar & - & 40 \\
\hline BANKANAME & varchar & - & 50 \\
\hline
\end{tabular}

Tabel Transaction digunakan untuk menampung data pemesanan paket wisata yang dilakukan oleh customer pada aplikasi e-tourism.

\section{Tabel Tambahan}

Tabel tambahan merupakan tabel bawaan dari library gammu yang digunakan untuk menampung data sms masuk, sms keluar dan sms terkirim.

\begin{tabular}{|c|c|c|c|}
\hline Field Name & Datatype & & Len \\
\hline UpdatedinDB & timestamp & $\nabla$ & \\
\hline ReceivingDateTime & timestamp & $\nabla$ & \\
\hline Text & text & $\nabla$ & \\
\hline Senderllumber & varchar & & 20 \\
\hline Coding & enum & $\sigma$ & 'Default_No_Compression' \\
\hline UDH & text & $\nabla$ & \\
\hline SMSCNumiber & varchar & & 20 \\
\hline Class & int & 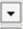 & 11 \\
\hline TextDecoded & text & $\nabla$ & \\
\hline ID & int & & 10 \\
\hline RecipientID & text & $\nabla$ & \\
\hline Processed & enum & F & 'false', 'true' \\
\hline terproses & enum & - & 'belum', 'sudah' \\
\hline
\end{tabular}

Tabel inbox digunakan untuk menampung data sms yang di kirim oleh customer.

Tabel 6.Tabel Outbox

\begin{tabular}{|c|c|c|c|}
\hline Field Name & Datatype & & Ien \\
\hline UpdatedInDB & timestanp & 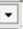 & \\
\hline InsertintoDB & timestamp & $\nabla$ & \\
\hline SendingDateTime & timestamp & $\nabla$ & \\
\hline Iext & text & 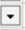 & \\
\hline DestinationNurber & varchar & & 20 \\
\hline Coding & enum & 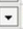 & 'Default_No_Compression', \\
\hline UDH & text & $\nabla$ & \\
\hline Class & int & & 11 \\
\hline IextDecoded & text & $\nabla$ & \\
\hline ID & int & & 10 \\
\hline Multipart & enum & 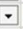 & 'false', 'true' \\
\hline RelativeValidity & int & & 11 \\
\hline SenderID & varchar & $\nabla$ & 255 \\
\hline SendingTimeout & timestamp & $\nabla$ & \\
\hline DeliveryReport & enum & 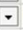 & 'default', 'yes', 'no' \\
\hline CreatorID & text & $\nabla$ & \\
\hline
\end{tabular}


Tabel outbox digunakan untuk menampung data sms yang akan dikirimkan.

Tabel 7. Tabel sentitems

\begin{tabular}{|c|c|c|c|}
\hline & & & \\
\hline Field tame & |Datatype & & ILen \\
\hline InsertIntodB & timestamp & 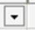 & \\
\hline SendingDateIime & timestamp & $\nabla$ & \\
\hline DeliveryDateTime & timestamp & $\nabla$ & \\
\hline Text & text & $\nabla$ & \\
\hline DestinationNumber & varchar & 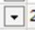 & 20 \\
\hline Coding & enum & $\nabla$ & 'Default_Ho_Compression' \\
\hline UDH & text & $\nabla$ & \\
\hline SMSCliumber & varchar & $\nabla^{2}$ & 20 \\
\hline Class & int & $\nabla$ & 11 \\
\hline TextDecoded & text & $\overline{7}$ & \\
\hline ID & int & $\nabla$ & 10 \\
\hline SenderID & varchar & $\nabla$ & 255 \\
\hline SequencePosition & int & $\nabla$ & 11 \\
\hline Status & enum & 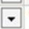 & 'SendingoK', 'Sendingokio \\
\hline StatusError & int & 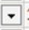 & 11 \\
\hline IPMR & int & (F) & 11 \\
\hline RelativeValidity & int & $\nabla$ & 11 \\
\hline CreatorID & text & 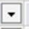 & \\
\hline
\end{tabular}

Tabel sentitems digunakan untuk menampung data sms yang sudah dikirimkan.

\subsection{Pemodelan Proses}

\subsubsection{Proses Pendaftaran Member}

Diagram activity ini menjelaskan mengenai fungsi yang akan digunakan untuk melakukan pendaftaran yang dilakukan oleh aktor user sebagai pelanggan baru.

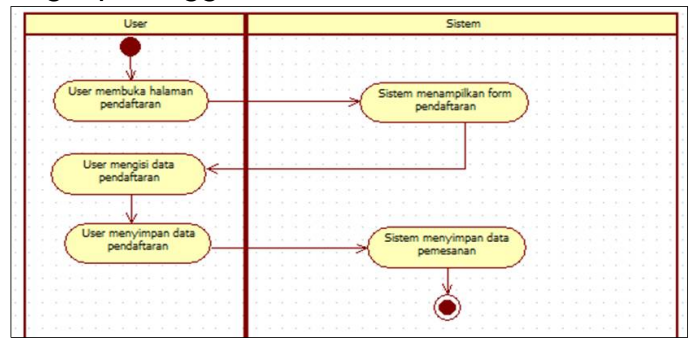

Gambar 5. Proses Pendaftaran Member

\subsubsection{Proses Mengubah Password}

Diagram activity ini menjelaskan mengenai fungsi yang akan digunakan untuk melakukan perubahan password yang dilakukan oleh aktor user sebagai pelanggan yang sudah terdaftar.

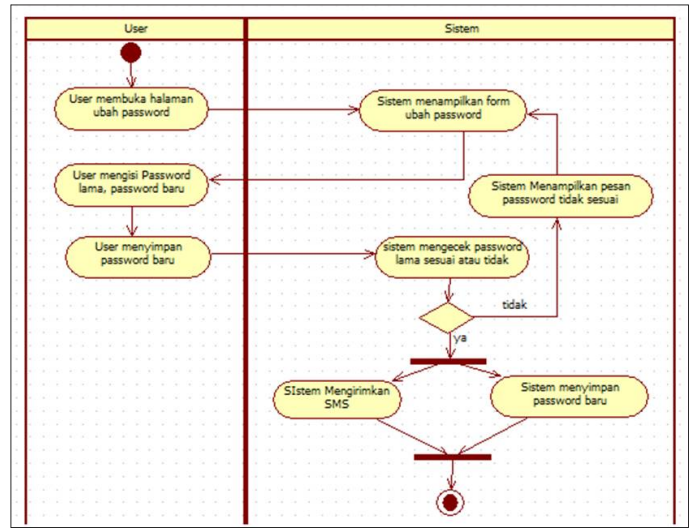

Gambar 6. Proses Mengubah Password

\subsubsection{Proses Pemesanan Paket Wisata}

Diagram activity ini menjelaskan mengenai fungsi yang akan digunakan untuk melakukan pemesanan paket wisata yang dilakukan oleh aktor user sebagai customer dimulai dari membuka halaman pemesanan, mengisi data pemesanan sampai system menyimpan data pesanan serta mengirim SMS.

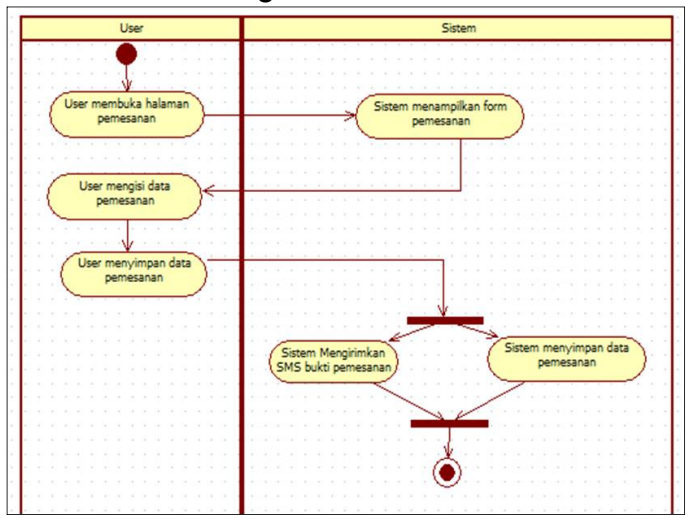

Gambar 7. Proses Pemesanan Paket Wisata

\subsubsection{Proses Pengelolaan Admin}

Diagram activity ini menjelaskan mengenai fungsi yang akan digunakan untuk melakukan pengelolaan administrasi web yang dilakukan oleh aktor user sebagai admin dimulai dari membuka halaman utama dan memilih pengelolaan web admin yang terdiri dari data customer, data paket wisata, data transaksi serta data laporan.

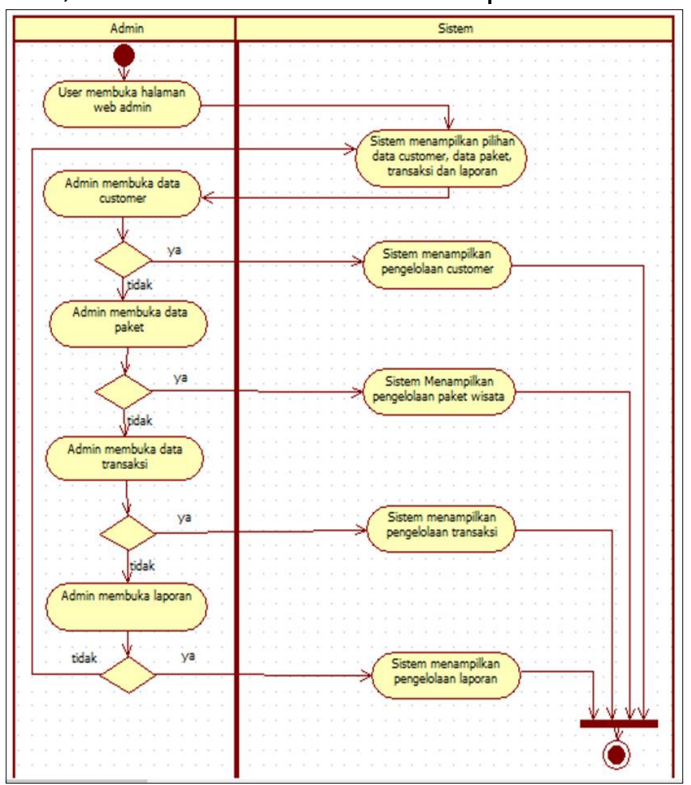

Gambar 8. Proses Pengelolaan Admin 


\subsection{Generalisasi Aplikasi}

\subsubsection{Halaman Pendaftaran Member}

Halaman pendaftaran digunakan untuk mendaftar user yang ingin menjadi member dengan cara mengisikan data pribadi mulai dari nama, alamat, telepon, nama bank yang akan digunakan untuk transaksi, nomor rekening dan password. Setelah data lengkap pilih tombol daftar untuk menyimpan data.

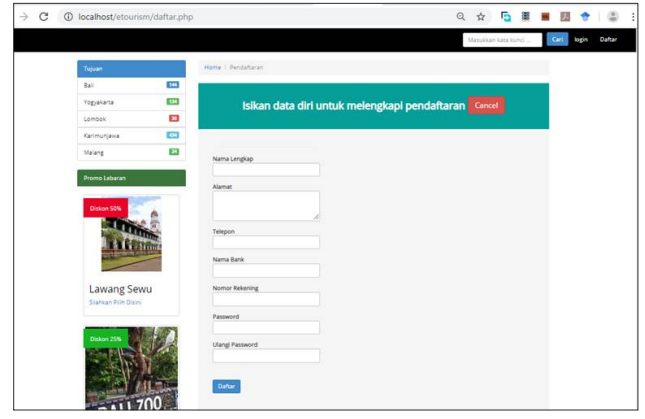

Gambar 9. Halaman Pendaftaran Member

\subsubsection{Halaman Mengubah Password}

Jika ingin merubah password member dengan cara mengisikan password lama dan mengisi password baru sebanyak dua kali, kemudian memilih update untuk melakukan perubahan.

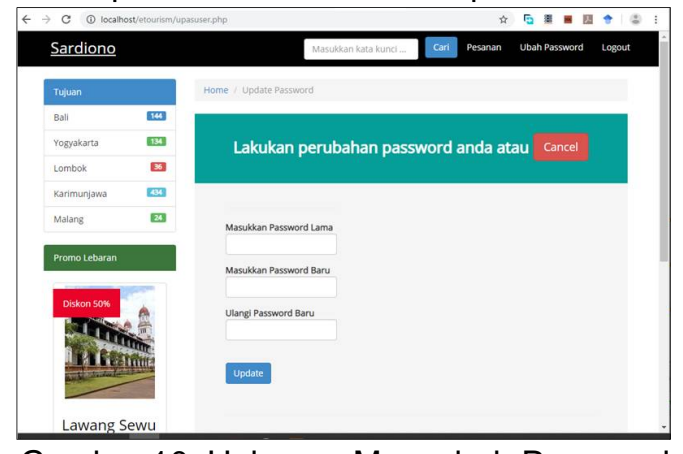

Gambar 10. Halaman Mengubah Password

\subsubsection{Halaman Pemesanan Paket Wisata}

Untuk melakukan pemesanan hal pertama yang harus dilakukan adalah memilih tujuan wisata mana yang akan dipesan. Setelah terpilih akan muncul pilihan daftar paket wisata yang akan di pesan. Jika ingin melanjutkan memesan pilih tombol tambah pesanan kemudian isikan jumlah pesanan yang di inginkan dan pilih tombol selesai.

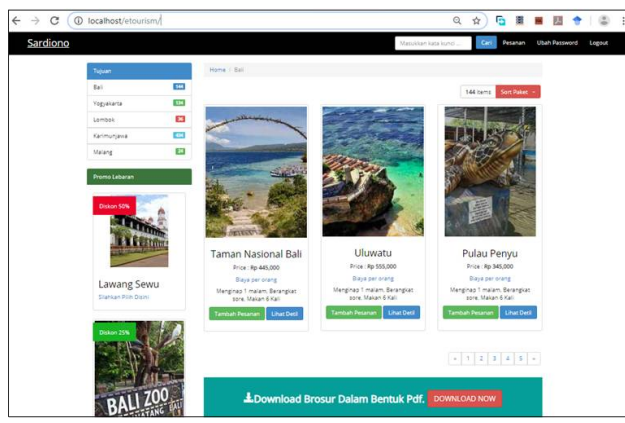

Gambar 11. Halaman Pemesanan Paket Wisata

\subsubsection{Halaman Pengelolaan Admin}

Semua administrasi web dilakukan dihalaman ini dengan cara login terlebih dahulu sebagai admin. Setelah berhasil akan muncul halaman utama yang terdiri dari pengelolaan data customer, data paket wisata, data transaksi serta data laporan. Didalam pengelolaan data dapat melakukan penambahan, pengubahan dan penghapusan data.

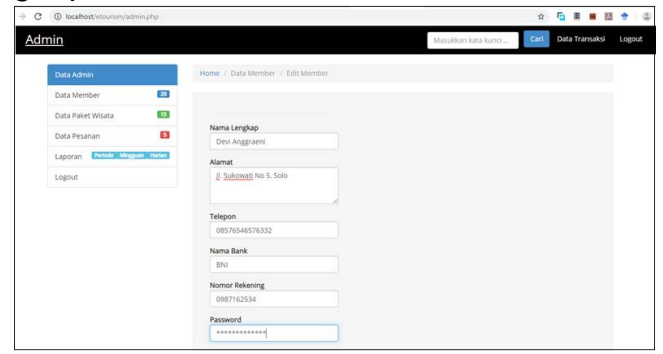

Gambar 12. Halaman Pemesanan Paket Wisata

\subsection{Pengujian}

Pengujian digunakan untuk mengetahui apakah program yang akan digunakan sudah berjalan secara maksimal. Untuk itu serangkaian unit program tersebut harus di uji terlebih dahulu agar program berjalan sesuai dengan yang diharapkan. Sebelum aplikasi dijalankan yang harus di lakukan pertama kali adalah menghubungkan Komputer dengan handphone atau modem.

\subsubsection{Pengujian Hardware}

Pada pengujian ini dilakukan cek kondisi hardware yang dibutuhkan untuk aplikasi ini. Setelah komputer menyala dan modem terpasang cek koneksi komputer dengan modem yang terpasang dengan melalui device manager. Hasil pengujian dinyatakan valid dapat dilihat pada gambar 13. 


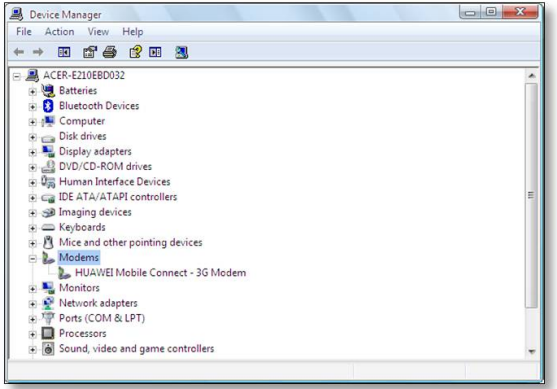

Gambar 13. Pengujian Modem

\subsubsection{Pengujian Web Server dan Database}

Pengujian ini dilakukan untuk pengecekan software server yang digunakan untuk menjalankan web dan database sebagai penyimpan data. Hasil pengujian dapat berjalan dan dinyatakan valid dapat dilihat pada gambar 14.

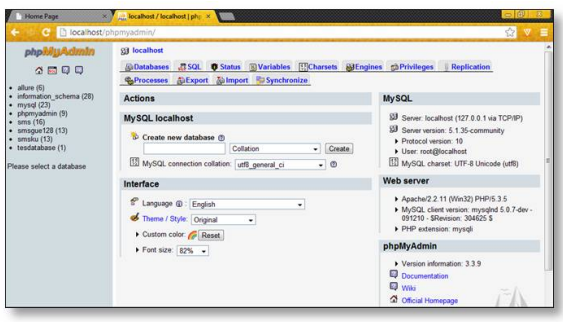

Gambar 14. Pengujian server web dan database

\subsubsection{Pengujian Server SMS Gateway}

Pengujian yang dilakukan untuk mengecek Service Gammu SMS Gateway. Hasil pengujian dapat berjalan dan dinyatakan valid dapat dilihat pada gambar 15 .

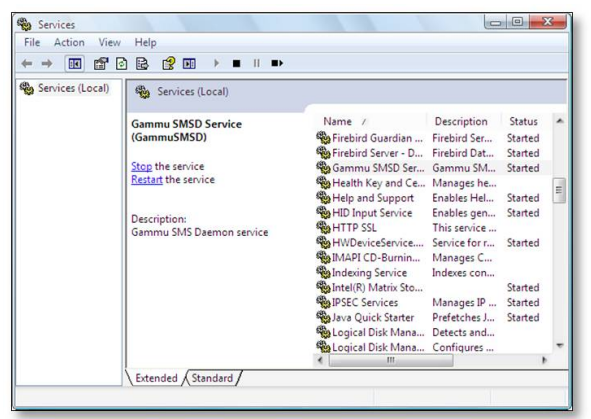

Gambar 15. Pengujian Service Gammu SMS Gateway

\subsubsection{Pengujian Halaman User}

Pengujian halaman user untuk mengelola data password dan untuk melakukan pesanan. Hasil pengujian dapat berjalan dan dinyatakan valid dapat dilihat pada gambar 16 .

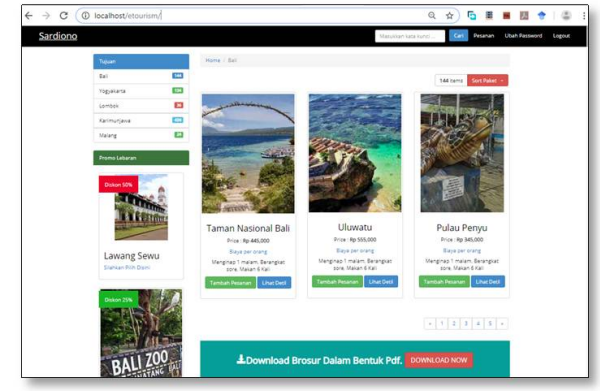

Gambar 16. Pengujian Halaman User

\subsubsection{Pengujian Halaman Admin}

Pengujian halaman administrasi untuk mengelola data customer, paket tour, transaksi, dan laporan. Hasil pengujian dapat berjalan dan dinyatakan valid dapat dilihat pada gambar 17 .

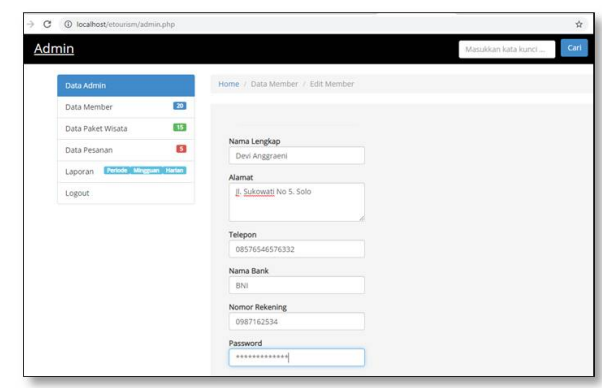

Gambar 17. Pengujian Halaman Admin

\subsubsection{Pengujian Sistem sms}

Integrasi dan pengujian system diuji dengan mengedit password dan melakukan transaksi pemesanan paket wisata. Hasilnya berupa autoreply program yang dapat mengirimkan SMS ke user. Hasil pengujian dapat berjalan dan dinyatakan valid dapat dilihat pada gambar 17 .

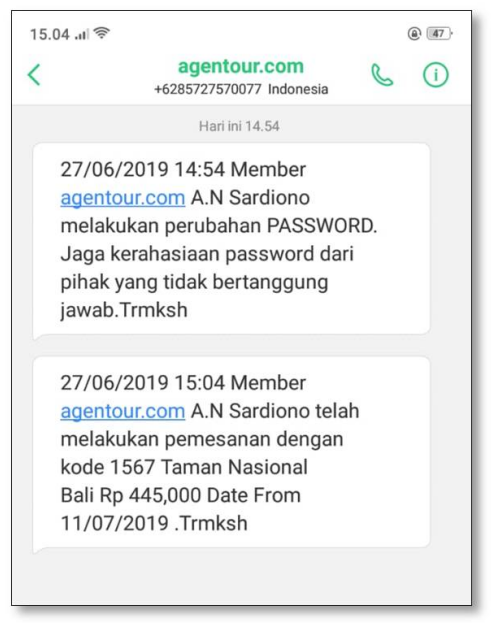

Gambar 18. Pengujian hasil SMS 
4. Kesimpulan dan saran

Berdasarkan hasil penelitian dan implementasi sistem maka dapat di ambil kesimpulan bahwa :

a. Telah di hasilkan aplikasi E-tourism yang didukung dengan SMS Gateway.

b. SMS dapat membackup informasi perubahan password dan info pesanan yang dilakukan oleh pelanggan

c. Dengan adanya aplikasi ini maka akan lebih memudahkan customer untuk mendapatkan informasi yang lebih valid, akurat dan cepat.

Beberapa saran yang dapat penulis berikan agar aplikasi dapat berjalan dengan lancer adalah:

a. Gunakan spesifikasi hardware yang tinggi agar akses komputer lebih cepat

b. Pilihlah sim card yang memiliki jaringan luas dan sinyal yang bagus.

\section{PUSTAKA}

[1]. Afrina, M., \& Ibrahim, A. (2015). Pengembangan Sistem Informasi SMS Gateway Dalam Meningkatkan Layanan Komunikasi Sekitar Akademika Fakultas IImu
Komputer Unsri. Jurnal Sistem Informasi Fasilkom Unsri, 852-864.

[2]. APJII. (2019). Penetrasi dan Perilaku Pengguna Internet Indonesia 2018. Retrieved from https://apjii.or.id/survei2018s

[3]. Arsul, Lumenta, A. S., \& Sugiarso, B. A. (2015). E-Tourism Kabupaten Pulau Morotai. E-Journal Teknik Elektro dan Komputer Universitas Sam Ratulangi, 71-78.

[4]. Internet World Stats. (2019). Top 20 Countries With The Highest Number of Internet Users. Retrieved from https://www.internetworldstats.com/top20.htm

[5]. Machdalena, S., Dewi, A. P., \& Soemantri, Y. S. (2018). The Lodge Maribaya Sebagai Salah Satu Pilihan Destinasi Ekowisata Kabupaten Bandung Barat. Jurnal Pariwisata Terapan UGM, 96-107.

[6]. Sriyanto, \& Sriyusielani, N. P. (2014). Perancangan Sistem Informasi Pemesanan Berbasis SMS Gateway Untuk Memperbaiki Informasi Persediaan (Studi Kasus : PT Indotirta Jaya Abadi Semarang). Jurnal Simetris, 143-152.

[7]. Utami, F. H., \& Asnawati. (2015). Rekayasa Perangkat Lunak. Yogyakarta: DePublish. 